\title{
Choosing an appropriate glomerular filtration rate estimating equation: role of body mass index
}

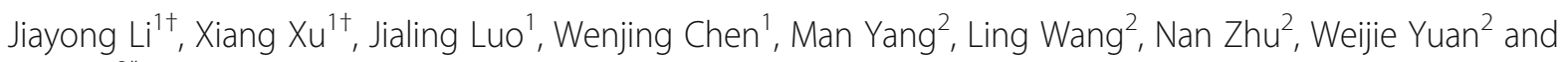
Lijie $\mathrm{Gu}^{2^{*}}$

\begin{abstract}
Background: We aimed to investigate the accuracy of different equations in evaluating estimated glomerular filtration rate (eGFR) in a Chinese population with different BMl levels.

Methods: A total of 837 Chinese patients were enrolled, and the eGFRs were calculated by three Chronic Kidney Disease Epidemiology Collaboration (CKD-EPI) equations, three full-age spectrum (FAS) equations and two Modification of Diet in Renal Disease (MDRD) equations. Results of measured GFR (mGFR) by the 99Tcmdiathylenetriamine pentaacetic acid (99Tcm-DTPA) renal dynamic imaging method were the reference standards. According to $\mathrm{BMI}$ distribution, the patients were divided into three intervals: below 25th(BMl 25$)$, 25th to 75th(BMl $\left.\right|_{\text {P25-75 }}$ ) and over 75th percentiles (BMl ${ }_{\text {P75 }}$ ).

Results: The medium BMI of the three BMI intervals were 20.9, 24.8 and $28.9 \mathrm{~kg} / \mathrm{m}^{2}$, respectively. All deviations from mGFR (eGFR) were correlated with BMI $(p<0.05)$. The percentage of cases in which eGFR was within $\mathrm{mGFR} \pm 30 \%$ (P30) was used to represent the accuracy of each equation. Overall, eGFRFAS_Cr_cysC and eGFREPI_Cr_2009 performed similarly, showing the best agreement with mGFR among the eight equations in Bland-Altman analysis (biases: 4.1 and $-4.2 \mathrm{~mL} / \mathrm{min} / 1.73 \mathrm{~m}^{2}$, respectively). In BMlP25 interval, eGFRFAS_cr got -0.7 of the biases with $74.2 \%$ of P30, the kappa value was 0.422 in classification of CKD stages and the $A \cup C_{60}$ was 0.928 in predicting renal insufficiency, and eGFREPI_Cr_2009 got 2.3 of the biases with 71.8\% of P30, the kappa value was 0.418 in classification of CKD stages and the $\mathrm{AUC}_{60}$ was 0.920 in predicting renal insufficiency. In BMlp25-75 interval, the bias of eGFRFAS_Cr_CysC was 4.0 with $85.0 \%$ of P30, the kappa value was 0.501 and the $A U C_{60}$ was 0.941 , and eGFR FAS_Cr_CysC $_{\text {s }}$ showed balanced recognition ability of each stage of CKD $(62.3,63.7,68.0,71.4$ and $83.3 \%$ respectively). In BMl 75 interval, the bias of eGFREPI_Cr_CysC_2012 was 3.8 with 78.9\% of P30, the kappa value was 0.484 the $\mathrm{AUC}_{60}$ was 0.919 , and EGFREPI_Cr_CysC_2012 equation showed balanced and accurate recognition ability of each stage $(60.5,60.0,71.4,57.1$ and 100\% respectively). In BMl 775 interval, the bias of eGFRFAs_cr_cysC was -1.8 with $78.5 \%$ of P30, the kappa value was 0.485 , the $\mathrm{AUC}_{60}$ was 0.922 . However, the recognition ability of each stage of eGFRFAS_Cr_CysC eq. (71.1, 61.2, 70.0, 42.9 and 50.0\% respectively) was not as good as GFREPI_Cr_CysC_2012 equation.
\end{abstract}

\footnotetext{
* Correspondence: lijiegu82@126.com

${ }^{+}$Jiayong Li and Xiang Xu contributed equally to this work.

${ }^{2}$ Department of Nephrology, Shanghai General Hospital, Shanghai Jiao Tong University School of Medicine, Shanghai 200080, China

Full list of author information is available at the end of the article
}

(c) The Author(s). 2021 Open Access This article is licensed under a Creative Commons Attribution 4.0 International License, which permits use, sharing, adaptation, distribution and reproduction in any medium or format, as long as you give appropriate credit to the original author(s) and the source, provide a link to the Creative Commons licence, and indicate if changes were made. The images or other third party material in this article are included in the article's Creative Commons licence, unless indicated otherwise in a credit line to the material. If material is not included in the article's Creative Commons licence and your intended use is not permitted by statutory regulation or exceeds the permitted use, you will need to obtain permission directly from the copyright holder. To view a copy of this licence, visit http://creativecommons.org/licenses/by/4.0/. The Creative Commons Public Domain Dedication waiver (http://creativecommons.org/publicdomain/zero/1.0/) applies to the data made available in this article, unless otherwise stated in a credit line to the data. 
Conclusion: For a Chinese population, we tend to recommend choosing eGFRFAS_Cr and eGFREPI_Cr_2009 when BMl was around 20.9, eGFR FAS_Cr_CysC when BMI was near 24.8, and eGFREPI_Cr_CysC_2012 when BMI was about 28.9.

Keywords: Body mass index, Estimated glomerular filtration rate, Chronic kidney disease

\section{Introduction}

Chronic kidney disease (CKD) is defined as a reduced glomerular filtration rate (GFR), increased urinary albumin excretion, or both, and has been recognized as an increasing public health issue worldwide [1]. Rising prevalence, poor outcomes, and high costs of CKD have led to considerable social and economic burdens in both developed and developing countries. Prevalence of CKD is estimated to be $8-16 \%$ worldwide [2]. In 2017, there were 132.3 million $[95 \%$ confidence interval $(95 \% \mathrm{CI})$ 121.8 to 143.7] people were diagnosed as CKD in China [3]. Therefore, the early prevention and accurate detection of CKD are particularly important.

Ideally, GFR should be measured. Measured (m) GFR gives an accurate assessment of kidney function and avoids confounding by interactions with variables, such as age or weight. Tc-99 m DTPA renal dynamic scintigraphy is a useful tool for clinicians in assessing renal function [4]. Because of the complicated process and nuclear pollution of above method, estimated GFR (eGFR) was considered as a convenient and no-invasive means which had been widely used in clinical diagnosis and treatment.

Many eGFR equations are based on the creatinine or/and cystatin $\mathrm{C}$ concentrations in serum. However, multiple factors such as muscle mass, weight, race, sex, gender and other individual differences affect the levels of serum creatinine [5]. Performance of Modification of Diet in Renal Disease (MDRD) and Chronic Kidney Disease Epidemiology Collaboration (CKD-EPI) equations remains suboptimal for estimating GFR in obese populations [6, 7]. Serum cystatin $\mathrm{C}$ also has the disadvantage in obesity population. Enlarged adipose tissues lead to elevation of serum cystatin $C$ [8]. In fact, overweight and obesity account for a large proportion in CKD, while the muscle percentage is not synchronized with body weight. Therefore, the accuracy of eGFR assessments is affected by irregular fluctuation in creatinine and cystatin C.

How to choose an appropriate eGFR equation which can estimate renal function accurately? We used the body mass index (BMI) as the breakthrough point. There are many researches on the comparison of different eGFR equations, but still lack of researches on which special equation should be recommended in certain BMI range. In the present study, we assessed the accuracy of eight eGFR equations [CKD-EPI cr_2009 (eGFR EPI_Cr_2009) [9], CKD-EPI cys_2012 (eGFR EPI_CysC_2012) [1], CKD-EPI cr_cys_ 2012 (eGFR EPI_Cr_CysC_2012) $_{\text {(1) }}$ [10]], three full age spectrum (FAS) equations (eGFR FAS _Cr, eGFR $_{\mathrm{FAS}}$ _CysC, and eGFR ${ }_{\mathrm{FAS}}$ Cr_CysC $)$ [11], abbreviated_MDRD (eGFR $\left.{ }_{a \_M D R D}\right) \quad[12]$, and Chinese_MDRD $\left(\mathrm{GGFR}_{\mathrm{C} \_M D R D}\right)$ [13] compared with GFR measurement using 99Tcm-DTPA scintigraphy. Our research aimed to identify which equation performed better at estimating GFR and ideally predicting the CKD stage in the corresponding BMI interval, and finally, provide credible eGFR in certain BMI intervals to the clinicians.

\section{Methods \\ Participants}

A total of 904 patients who underwent GFR measurement using 99Tcm-diathylenetriamine pentaacetic acid (99Tcm-DTPA) scintigraphy from January 2016 to September 2017 in Shanghai General Hospital, were observed. Exclusion criteria included amputation, pregnant women, obstructive nephropathy, solitary kidney or a single kidney, urinary tract infection, acute kidney injury, any history of malignancy or kidney surgery, hyperthyroidism, use of antibacterial agents within 2 weeks, and malignant hypertension. Finally, a total of 837 patients were enrolled in this study. General characteristics were included such as sex, age, body mass index (BMI), serum creatinine, serum cystatin C, measured GFR (mGFR) and the situation of basic diseases. BMI was calculated following the equation: BMI $\left(\mathrm{Kg} / \mathrm{m}^{2}\right)=$ weight $(\mathrm{kg})$ $/$ height $^{2}(\mathrm{~m})$. Three intervals were divided based on BMI percentiles, percentile $25 \%\left(\mathrm{BMI}_{\mathrm{P} 25}\right)$, percentile $25 \%$ $75 \%\left(\mathrm{BMI}_{\mathrm{P} 25-75}\right)$ and percentile $75 \%\left(\mathrm{BMI}_{\mathrm{P} 75}\right)$. Research has been conducted in accordance with the Declaration of Helsinki and was approved by the Ethics Committee of Shanghai General Hospital. Written informed consent was obtained from all participants. All methods were carried out in accordance with the relevant guidelines and regulations.

\section{Measurement of reference GFR (mGFR)}

The mGFR was measured by gate's method of radionuclide renal dynamic imaging. The instrument used Siemens Excel Evo SPECT which equipped with low energy and high resolution parallel hole collimator, energy peak $140 \mathrm{keV}$, window width $\pm 20 \%$. 99TcmDTPA 
(radiochemical purity, > 95\%; percentage of 99TcmDTPA bound to plasma protein, $<5 \%$ ) was provided by Shanghai Atom Kexing Pharmaceutical Co., Ltd., China. Determined the mGFR by gate's method.

\section{Definition of renal insufficiency and CKD classification}

The definition of renal insufficiency and CKD classification were referred to the 2012 KDIGO clinical practice guideline [1]. Renal insufficiency was defined as mGFR $<60 \mathrm{~mL} / \mathrm{min} / 1.73 \mathrm{~m}^{2}$. CKD was classified into five stages based on the mGFR values as follows: stage 1, mGFR $\geq 90 \mathrm{~mL} / \mathrm{min} / 1.73 \mathrm{~m}^{2} ; \quad$ stage $2, \quad 60 \mathrm{~mL} / \mathrm{min} / 1.73 \mathrm{~m}^{2} \leq$ $\mathrm{mGFR}<90 \mathrm{~mL} / \mathrm{min} / 1.73 \mathrm{~m}^{2}$; stage $3,30 \mathrm{~mL} / \mathrm{min} / 1.73$ $\mathrm{m}^{2} \leq \mathrm{mGFR}<60 \mathrm{~mL} / \mathrm{min} / 1.73 \mathrm{~m}^{2} ;$ stage $4,15 \mathrm{~mL} / \mathrm{min} /$ $1.73 \mathrm{~m}^{2} \leq \mathrm{mGFR}<30 \mathrm{~mL} / \mathrm{min} / 1.73 \mathrm{~m}^{2} ;$ stage $5, \mathrm{mGFR}<$ $15 \mathrm{~mL} / \mathrm{min} / 1.73 \mathrm{~m}^{2}$.

\section{Measurement of serum creatinine (Scr) and cystatin C (CysC) levels and GFR-estimating equations}

Blood samples were obtained after the patients had fasted for $12 \mathrm{~h}$. Both Scr and $\mathrm{CysC}$ were measured by an automatic biochemical autoanalyzer (Cobas 8000; Roche Products Ltd. Basel, Switzerland), used original matching assay kit (Roche Diagnostics, Mannheim, Germany). Based on the Scr, eGFR was calculated by CKD-EPI Cr_2009 (eGFR EPI_Cr_2009) [9], FAS Cr (eGFR FAS_Cr) $_{\text {[ }}$ [11], abbreviated _MDRD (eGFR

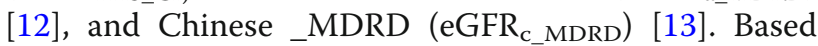
on the CysC, eGFRs was calculated by CKD-EPI CysC_2012 (eGFR EPI_CysC_2012) [1] and FAS CysC $\left(\right.$ eGFR $_{\left.\mathrm{FAS} \_\mathrm{CysC}\right)}$ [11]. Based on both $\mathrm{SCr}$ and CysC, eGFR was calculated by CKD-EPI Cr_CysC_2012 (eGFR EPI_Cr_CysC_2012) $_{\text {) [10] }}$ and FAS Cr_CysC (eGFRFAS _Cr_CysC) [11].

The equations used in the study population (with no correction for race and ethnicity) were the following ( $\mathrm{SCr}$ indicates serum creatinine):

(1) CKD-EPI Cr_2009 equation:

Female, $\mathrm{SCr} \leq 61.88 \mu \mathrm{mol} / \mathrm{L}:$ eGFR

$$
\begin{aligned}
=144 & \times(\mathrm{SCr} / 61.88)^{-0.329} \times 0.993^{\text {age }} \\
& \times(1.159 \text { ifblack })
\end{aligned}
$$

Female, $\mathrm{SCr}>61.88 \mu \mathrm{mol} / \mathrm{L}:$ eG FR

$$
\begin{aligned}
=144 & \times(\mathrm{SCr} / 61.88)^{-1.209} \times 0.993^{\text {age }} \\
& \times(1.159 \text { ifblack })
\end{aligned}
$$

Male, $\mathrm{SCr} \leq 79.56 \mu \mathrm{mol} / \mathrm{L}:$ eGFR

$$
\begin{aligned}
=141 & \times(\mathrm{SCr} / 79.56)^{-0.411} \times 0.993^{\mathrm{age}} \\
& \times(1.159 \mathrm{ifblack})
\end{aligned}
$$

Male, $\mathrm{SCr}>79.56 \mu \mathrm{mol} / \mathrm{L}:$ eGFR

$$
\begin{aligned}
=141 & \times(\mathrm{SCr} / 79.56]^{-1.209} \times 0.993^{\text {age }} \\
& \times(1.159 \text { ifblack })
\end{aligned}
$$

Female, $\mathrm{SCr} \leq 61.88 \mu \mathrm{mol} / \mathrm{L}$ and $\mathrm{SCys} \leq 0.8 \mathrm{mg} / \mathrm{dL}:$ eGFR $=130$

$$
\times(\mathrm{Scr} / 61.88)^{-0.248} \times(\mathrm{Scyst} / 0.8)^{-0.375} \times 0.995^{\text {age }} \times(1.08 \text { if black })
$$

Female, $\mathrm{SCr} \leq 61.88 \mu \mathrm{mol} / \mathrm{L}$ and SCys $>0.8 \mathrm{mg} / \mathrm{dL}:$ eGFR $=130$

$$
\times(\mathrm{Scr} / 61.88)^{-0.248} \times(\text { Scyst } / 0.8)^{-0.711} \times 0.995^{\text {age }} \times(1.08 \text { if black })
$$

Female, $\mathrm{SCr}>61.88 \mu \mathrm{mol} / \mathrm{L}$ and $\mathrm{SCys} \leq 0.8 \mathrm{mg} / \mathrm{dL}:$ eGFR $=130$

$$
\times(\mathrm{Scr} / 61.88)^{-0.601} \times(\text { Scyst } / 0.8)^{-0.375} \times 0.995^{\text {age }} \times(1.08 \text { if black })
$$

Female, $\mathrm{SCr}>61.88 \mu \mathrm{mol} / \mathrm{L}$ and SCys $\geq 0.8 \mathrm{mg} / \mathrm{dL}:$ eGFR $=130$

$$
\times(\text { Scr } / 61.88)^{-0.601} \times(\text { Scyst } / 0.8)^{-0.711} \times 0.995^{\text {age }} \times(1.08 \text { if black })
$$

Male, $\mathrm{SCr} \leq 79.56 \mu \mathrm{mol} / \mathrm{L}$ and $\mathrm{SCys} \leq 0.8 \mathrm{mg} / \mathrm{dL}:$ eGFR $=135$

$$
\times(\mathrm{Scr} / 79.56)^{-0.207} \times(\text { Scyst } / 0.8)^{-0.375} \times 0.995^{\text {age }} \times(1.08 \text { if black })
$$

Male, $\mathrm{SCr} \leq 79.56 \mu \mathrm{mol} / \mathrm{L}$ and SCys $>0.8 \mathrm{mg} / \mathrm{dL}:$ eGFR $=135$

$$
\times(\mathrm{Scr} / 79.56)^{-0.207} \times(\mathrm{Scyst} / 0.8)^{-0.711} \times 0.995^{\text {age }} \times(1.08 \text { if black })
$$

Male, $\mathrm{SCr}>79.56 \mu \mathrm{mol} / \mathrm{L}$ and $\mathrm{SCys} \leq 0.8 \mathrm{mg} / \mathrm{dL}: \mathrm{eGFR}=135$

$$
\times(\mathrm{Scr} / 79.56)^{-0.601} \times(\text { Scyst } / 0.8)^{-0.375} \times 0.995^{\text {age }} \times(1.08 \text { if black })
$$

Male, $\mathrm{SCr}>79.56 \mu \mathrm{mol} / \mathrm{L}$ and SCys $>0.8 \mathrm{mg} / \mathrm{dL}:$ eGFR $=135$

$$
\times(\mathrm{Scr} / 79.56)^{-0.601} \times(\text { Scyst } / 0.8)^{-0.711} \times 0.995^{\text {age }} \times(1.08 \text { if black })
$$

(3) CKD-EPI CysC_2012 equation:

$$
\begin{aligned}
\text { SCys } & \leq 0.8 \mathrm{mg} / \mathrm{L}: \text { eGFR }=133 \times(\text { Scyst } / 0.8)^{-0.499} \\
& \times 0.996^{\text {age }}(\times 0.932 \text { if female }) \text { SCys }>0.8 \mathrm{mg} / \mathrm{L}: \\
& \mathrm{eGFR}=133 \times(\text { Scys } / 0.8)^{-1.328} \times 0.996^{\text {age }}(\times 0.932 \text { if female })
\end{aligned}
$$

(4) FAS Cr equation:

$$
\begin{aligned}
\mathrm{eGFR}= & 107.3 /(\mathrm{SCr} / \mathrm{QCys}) \times\left[0.988^{(\text {age }-40)}, \text { when age }>40 \text { years }\right] \\
& (\text { female }: \text { QScr }=0.70 \mathrm{mg} / \mathrm{dl} ; \text { male }: \text { QScr }=0.90 \mathrm{mg} / \mathrm{dl})
\end{aligned}
$$

(5) FAS CysC equation:

$$
\begin{gathered}
\text { eGFR }=107.3 /(\text { SCys } / \text { QCys }] \times\left[0.988^{(\text {age-40)}} \text { when age }>40 \text { years }\right] \\
(\text { age }<70 \text { years old }: \text { QCys }=0.82 \mathrm{mg} / \mathrm{l} ; \text { age } \geq 70 \text { years old : } \\
\text { QCys }=0.95 \mathrm{mg} / \mathrm{l})
\end{gathered}
$$

(6) FAS Cr-CysC equation:

$$
\begin{aligned}
\mathrm{eGFR}= & 107.3 /[\alpha \times(\mathrm{SCr} / \mathrm{QScr})+(1-\alpha) \times(\mathrm{SCys} / \mathrm{QCys})] \\
& \times\left[0.988^{(\text {age-40)}} \text { when age }>40 \text { years }\right] \\
& (\text { female }: \text { QScr }=0.70 \mathrm{mg} / \mathrm{dl} ; \text { male }: \\
& \text { QScr }=0.90 \mathrm{mg} / \mathrm{dl} ; \text { age }<70 \text { years old }: \\
& \text { QCys }=0.82 \mathrm{mg} / \mathrm{l} ; \text { age } \geq 70 \text { years old }: \\
& \text { QCys }=0.95 \mathrm{mg} / \mathrm{l} ; \alpha=0.5)
\end{aligned}
$$

(7) abbreviated_MDRD equation:

$$
\begin{gathered}
\mathrm{eGFR}=175 \times \mathrm{SCr}(\mu \mathrm{mol} / \mathrm{L} \times 0.0011312)^{-1.154} \times \text { age }(\text { years })^{-0.203} \\
\times(0.742, \text { if female }) \times(1.212, \text { if black })
\end{gathered}
$$

(8) Chinese _MDRD equation:

$$
\begin{aligned}
\mathrm{eGFR}=175 \times & \mathrm{SCr}(\mu \mathrm{mol} / \mathrm{L} \times 0.0011312)^{-1.234} \times \text { age }(\text { years })^{-0.179} \\
& \times(0.79, \text { if female })
\end{aligned}
$$

(2) CKD-EPI CysC_2012 equation: 


\section{Statistical analysis}

Statistical analyses were performed using SPSS version 22.0 for Windows (SPSS Inc., Chicago, USA) and Medcalc 11.4 for windows. Kolmogorov-Smirnov test (K-S) was used to test the normality of variables [14]. Continuous variables were presented as the means \pm standard deviation and were analyzed using unpaired Student's ttests. Nonnormally distributed variables were presented as medians with corresponding 25th and 75th percentiles (interquartile ranges) and compared using the Mann-Whitney U test [15]. Wilcoxon test was used to compare the differences of the deviation from mGFR ( $\triangle$ eGFR, which is mGFR minus eGFR) by these eight eGFRs when in different BMI interval. Plotting scatter diagrams were used to observe the trend of each $\triangle \mathrm{eGFR}$ when in different BMI state. Partial correlation analysis was used to evaluate correlations between $\triangle$ eGFR and BMI. Bland-Altman analysis [16] was used to determine the agreement between the mGFR and eGFR values, similar to the study by Chi et al [17], which were calculated by different equations. The percentage of cases in which eGFR was within mGFR $\pm 30 \%$ (P30) was used to represent the accuracy of each equation. Kappa statistics were used to evaluate the agreement between stage classification from the mGFR values and from the eGFR values calculated by different equations, with the following interpretations: slight agreement $(0-0.20)$, fair agreement (0.21-0.40), moderate agreement (0.41-0.60), substantial agreement $(0.61-0.80)$, and almost perfect or perfect agreement $(0.81-1.0)$ [18]. The receiver operating characteristic (ROC) curve was used to determine the diagnostic power at predicting the renal insufficiency $\left(\mathrm{ROC}_{60}\right)$ by the eight different equations, with the results reported as the areas under the ROC curve $\left(\mathrm{AUC}_{60}\right)$, sensitivity, and specificity [19]. Differences with $P<0.05$ were considered statistically significant.

\section{Results}

\section{Overview of the entire study population}

The demographic and clinical features of the participants included in the analysis are listed in Table 1 . The medium BMI was $24.8 \mathrm{Kg} / \mathrm{m}^{2}$ which $25.1 \mathrm{Kg} / \mathrm{m}^{2}$ for male, and 24.2 for female. According to the percentile of $\mathrm{BMI}$, it was divided into three intervals, $<25 \%\left(\mathrm{BMI}_{\mathrm{P} 25}\right)$, $25 \% \sim 75 \%\left(\mathrm{BMI}_{\mathrm{P} 25-75}\right)$ and $>75 \%\left(\mathrm{BMI}_{\mathrm{P} 75}\right)$, respectively. The average BMI was $20.9 \mathrm{Kg} / \mathrm{m}^{2}$ in $\mathrm{BMI}_{\mathrm{P} 25}, 24.8 \mathrm{Kg} / \mathrm{m}^{2}$ in $\mathrm{BMI}_{\mathrm{P} 25-75}$, and $28.9 \mathrm{Kg} / \mathrm{m}^{2}$ in $\mathrm{BMI}_{\mathrm{P} 75}$ respectively. Among all the patients, $66.8 \%$ had diabetes and $64.5 \%$ had hypertension, and $71.6 \%$ had atherosclerosis which was the most common diagnosis. The average mGFR was $71.4 \pm 28.1 \mathrm{~mL} / \mathrm{min} / 1.73 \mathrm{~m}^{2}$, while the average eGFR varied according to different calculation formulas, ranging from $60.2(44.9,74.9) \mathrm{mL} / \mathrm{min} / 1.73 \mathrm{~m}^{2}$ to $88.5 \pm 49.1$ $\mathrm{mL} / \mathrm{min} / 1.73 \mathrm{~m}^{2}$.
Relation between BMI and $\triangle \mathrm{eGFR}$ based on different formulas

The correlation between $\triangle \mathrm{eGFR}$ based on different formulas and BMI was shown by plotting scatter diagrams of $\triangle \mathrm{eGFR}$ based on different formulas with the increase of BMI (Fig. 1). With the increase of BMI, trends of $\triangle \mathrm{eGFR}$ differed with diverse formulas. Partial correlation coefficient was shown in Table 2, which was statistically significant $\left(p=0.012\right.$ for ${ } \mathrm{eGFR}_{\mathrm{C} \_ \text {MDRD }}$ while the rest $p<0.001)$.

The comparison of $\triangle \mathrm{eGFR}$ among different BMI

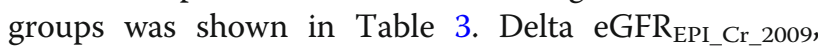
$\triangle \mathrm{eGFR}_{\mathrm{EPI} C \mathrm{Cys} C 2012}, \Delta \mathrm{eGFR} \mathrm{EPI}_{\mathrm{Er} \text { _CysC_2012, }}, \mathrm{eGFR}_{\mathrm{FAS} \_\mathrm{Cr}}$, $\triangle \mathrm{eGFR} \mathrm{FAS}_{\mathrm{F} \text { CysC }}$ and $\triangle \mathrm{eGFR} \mathrm{FAS}_{\mathrm{F} \text { Cr_CysC }}$ showed significant differences in different BMI intervals $(p=0.030,0.010$, $0.000,0.0029,0.000$ and 0.001 respectively). While $\triangle \mathrm{eGFR}_{\mathrm{a} \_\mathrm{MDRD}}$ and $\triangle \mathrm{eGFR}_{\mathrm{c} \_\mathrm{MDRD}}$ had no significant difference in different BMI intervals $(p=0.234$ and 0.522, respectively).

\section{Consistency of eGFRs compared with mGFR}

The consistency between the eGFR based on different formulas and the mGFR was analyzed by Bland-Altman plots (Fig. 2, Table 4). The accuracy of each equation was represented by the percentage of cases in which eGFR was within the range of mGFR $\pm 30 \%$ (P30). Compared with mGFR, biases of eGFR $\mathrm{FAS}_{-\mathrm{Cr}} \mathrm{CysC}_{\mathrm{C}}$ and $\mathrm{eGFR}_{\mathrm{E}-}$ PI_Cr_2009 (4.1 and -4.2 , respectively) were much less

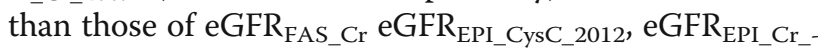
CysC_2012, eGFR FAS_CysC, $_{2}$ eGFR a_MDRD $_{-}$and $e G F R_{\text {__MDRD }}$ $(-6.9,8.4,9.6,10.8,-8.4$ and -20.8 , respectively). The accuracy of each eGFR was as follows: $81.5 \%$ for eGFR-

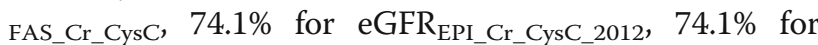
eGFR ${ }_{\text {EPI_CysC_2012, }}, 73.4 \%$ for eGFR $\overline{F A S}_{\text {FysC }}, 70.1 \%$ for eGFR EPI_Cr_2009, $_{2} \quad 69.3 \%$ for eGFR $_{\text {FAS_Cr }}, \quad 63.0 \%$ for eGFR $\mathrm{a} \_M D R D_{\text {and }}$ a $7.0 \%$ for $\mathrm{eGFR}_{\mathrm{c} \_\mathrm{MDRD}}$.

However, the accuracy of different formulas varied in different $\mathrm{BMI}$ intervals. In the $\mathrm{BMI}_{\mathrm{P} 25}$ interval, the bias

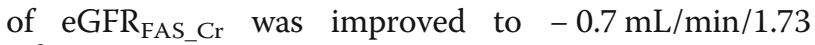
$\mathrm{m}^{2}(P=0.679)$ with $74.2 \%$ of P30. And the bias of eGFR PI_Cr_2009 was $2.3 \mathrm{~mL} / \mathrm{min} / 1.73 \mathrm{~m}^{2}(P=0.061)$ with $71.8 \%$ of P30. In the range of $\mathrm{BMI}_{\mathrm{P} 25-75}$, the bias of eGFRFAS_Cr_CysC was $4.0 \mathrm{~mL} / \mathrm{min} / 1.73 \mathrm{~m}^{2}$ with $85.0 \%$ of $\mathrm{P} 30$, and the bias of eGFR with $74.7 \%$ of P30, which were most consistent with mGFR. In the BMI ${ }_{\text {P75 }}$ interval, the bias of eGFR EPI_Cr_- $_{-}$ Cys__2012 was $3.8 \mathrm{~mL} / \mathrm{min} / 1.73 \mathrm{~m}^{2}(P<0.01)$ with $78.9 \%$ of P30 and the bias of eGFR EPICysC 2012 was $3.3 \mathrm{~mL} /$ $\min / 1.73 \mathrm{~m}^{2} \quad(P<0.05)$ with $76.6 \%$ of $\mathrm{P} 30$. The bias of eGFR $_{\text {FAS_Cr_CysC }}$ was $-1.8 \mathrm{~mL} / \mathrm{min} / 1.73 \mathrm{~m}^{2}$, but there was no statistical significance $(P=0.095)$. It was suggested that the consistency of eGFR compared with the mGFR was the best when eGFR calculated by eGFR EPI_- $_{\text {- }}$ CysC_2012 and eGFR FAS_Cr_CysC $_{\text {formulas. }}$ 
Table 1 Baseline characteristics

\begin{tabular}{|c|c|c|c|}
\hline Variable & Total & $\operatorname{Male}(n=505)$ & $\operatorname{Female}(n=332)$ \\
\hline Age, years & $60(52,69)$ & $59(51,67)$ & $62(55,71) *$ \\
\hline Height, cm & $167(160.0,172.3)$ & $170(167,175)$ & $160(155,163) *$ \\
\hline Weight, kg & $69(60,77)$ & $74(66,81)$ & $61(54,69) *$ \\
\hline Body surface area (BSA), $\mathrm{m}^{2}$ & $1.81(1.67,1.95)$ & $1.90(1.80,2.01)$ & $1.66(1.56,1.77) *$ \\
\hline Body mass index (BMI), $\mathrm{Kg} / \mathrm{m}^{2}$ & $24.8(22.7,27.3)$ & $25.1(23.1,27.4)$ & $24.2(21.6,26.8) *$ \\
\hline $\mathrm{BMI}_{\mathrm{P} 25}, \mathrm{Kg} / \mathrm{m}^{2}(n=209)$ & $20.9(19.6,21.9)$ & & \\
\hline $\mathrm{BMI}_{\mathrm{P} 25-75}, \mathrm{Kg} / \mathrm{m}^{2}(n=419)$ & $24.8(23.7,25.9)$ & & \\
\hline $\mathrm{BMI}_{\mathrm{P} 75}, \mathrm{Kg} / \mathrm{m}^{2}(\mathrm{n}=209)$ & $28.9(28.0,30.6)$ & & \\
\hline Serum creatinine $(\mathrm{s} C r), \mu \mathrm{mol} / \mathrm{L}$ & $79(61,113.3)$ & $86(68,120)$ & $66(51,100) *$ \\
\hline Serum uric acids (sUA), $\mu \mathrm{mol} / \mathrm{L}$ & $360(289,435)$ & $380(311,449)$ & $323(268,421) *$ \\
\hline Serum urea (sUrea), mmol/L & $6.3(5.0,8.6)$ & $6.5(5.2,8.6)$ & $6.1(4.8,8.8)^{\Delta}$ \\
\hline Serum cystatin C (sCysc), mg/L & $1.17(0.97,1.53)$ & $1.18(0.99,1.53)$ & $1.16(0.94,1.58)^{\Delta}$ \\
\hline Urinary albumin creatinine ratio (ACR), $\mu \mathrm{g} / \mathrm{mg}$ & $64.4(18.3,458.5)$ & $73.8(15.7,522.8)$ & $60.2(23.9,406.1)^{\Delta}$ \\
\hline ACR $\geq 30 \mu \mathrm{g} / \mathrm{mg}$ rate, $\%$ & 64.03 & 62.80 & $66.10^{\Delta}$ \\
\hline Diabetes & $559(66.8 \%)$ & $373(73.9 \%)$ & $186(56.0 \%)^{*}$ \\
\hline Hypertension & $540(64.5 \%)$ & 325 (64.4\%) & $215(42.6 \%)^{\Delta}$ \\
\hline coronary heart disease & 165 (19.7\%) & $102(20.2 \%)$ & $63(12.5 \%)^{\Delta}$ \\
\hline atherosclerosis & $599(71.6 \%)$ & $358(70.9 \%)$ & $241(47.7 \%)^{\Delta}$ \\
\hline mGFR, ml.min $-1 \cdot 1.73 \mathrm{~m} 2$ & $71.4 \pm 28.1$ & $69.8 \pm 27.3$ & $73.8 \pm 29.2^{\mathbf{\Lambda}}$ \\
\hline \multicolumn{4}{|l|}{ distribution in each CKD stage } \\
\hline CKD1 & $221(26.4 \%)$ & $123(24.4 \%)$ & $98(29.5 \%)^{\Delta}$ \\
\hline CKD2 & $338(40.4 \%)$ & $214(42.4 \%)$ & $124(37.4 \%)^{\Delta}$ \\
\hline CKD3 & $212(25.3 \%)$ & $130(25.7 \%)$ & $82(24.7 \%)^{\Delta}$ \\
\hline CKD4 & $54(6.5 \%)$ & $28(5.5 \%)$ & $26(7.8 \%)^{\Delta}$ \\
\hline CKD5 & $12(1.4 \%)$ & $10(2.0 \%)$ & $2(0.6 \%)^{\Delta}$ \\
\hline \multicolumn{4}{|l|}{ eGFR } \\
\hline eGFR ${ }_{a \_M D R D}$ & $75.3(47.2,105.1)$ & $78.6(55.8,104.7)^{\star}$ & $78.2(48.0,110.0)^{\star \Delta}$ \\
\hline eGFR $R_{C \_}$MDRD & $88.5 \pm 49.1$ & $87.9 \pm 44.7^{\star}$ & $98.4 \pm 54.4^{\star \Delta}$ \\
\hline eGFREPI_Cr_2009 & $81.9(52.2,93.3)$ & $82.5(55.5,101.2) \star$ & $80.4(48.5,97.8) \star \star$ \\
\hline eGFREPI_Cr_CysC_2012 & $63.3(42.0,81.2)$ & $63.5(43.6,79.8) \star$ & $62.2(39.6,82.2) \star \Delta$ \\
\hline eGFREPI_CysC_2012 & $62.8(43.4,82.3)$ & $62.5(44.1,80.3) \star$ & $62.8(41.2,84.5){ }^{\star \Delta}$ \\
\hline eGFR $\mathrm{FAS}_{\text {_Cr }}$ & $77.7(51.6,104.0)^{\star}$ & $78.8 \pm 36.7^{\star}$ & $74.1(48.1,104.6)^{\square \Delta}$ \\
\hline eGFR FAS_CysC & $60.2(44.9,74.9)^{\star}$ & $60.8(45.9,73.9)^{\star}$ & $61.4 \pm 24.8^{\star \Delta}$ \\
\hline eGFR FASCr_CysC $_{\text {C }}$ & $66.8(47.8,85.6)^{\star}$ & $67.9 \pm 28.3^{\star}$ & $66.0(46.3,87.3){ }^{\star \Delta}$ \\
\hline
\end{tabular}

${ }^{{ }^{4} P}>0.05,{ }^{\triangle} P<0.05,{ }^{*} P<0.01$, compared with male; ${ }^{\star} P<0.01,{ }^{\square} P>0.05$, compared with mGFR

\section{Accuracy of eGFR in CKD staging in different BMI intervals}

The kappa values of eGFR EPI_Cr_2009, $_{\text {eGFR }}$ FAS_Cr and $\mathrm{eGFR}_{\mathrm{a} \_M D R D}$ were $\operatorname{similar}(0.418,0.422$ and 0.412 respectively), which were higher than that of other formulas when in $\mathrm{BMI}_{\mathrm{P} 25}$ interval (Supplemental Table 1). They showed high accuracy $(84.4,76.6$ and $88.3 \%$, respectively) in the identification of stage 1 CKD and moderate accuracy in the identification of stage 2 and 3 CKD. In $\mathrm{BMI}_{\mathrm{P} 25-75}$ interval, eGFR $\mathrm{FAS}_{-} \mathrm{Cr} \_\mathrm{CysC}$ had highest kappa value (0.504), which was higher than eGFR EPI_- $_{\text {- }}$ CysC_2012 (0.431), eGFR FAS_Cr $_{2}(0.415)$ and eGFR EPI_Cr_- $_{-}$ CysC_2012 (0.415). The eGFR FAS_Cr_CysC $_{\text {showed a better }}$ accuracy in the identification of stage 2 and 3 CKD (63.7 and $68.0 \%$ respectively) (Supplemental Table 2 ). In the $\mathrm{BMI}_{\mathrm{P} 75}$ interval, eGFREPI_Cr_CysC_2012 was found to be the best, with a kappa value of 0.484 , showing balanced and accurate recognition ability of each stage (60.5, 60.0, 71.4, 57.1 and 100\% respectively) (Supplemental Table 3). However, the recognition ability of each 

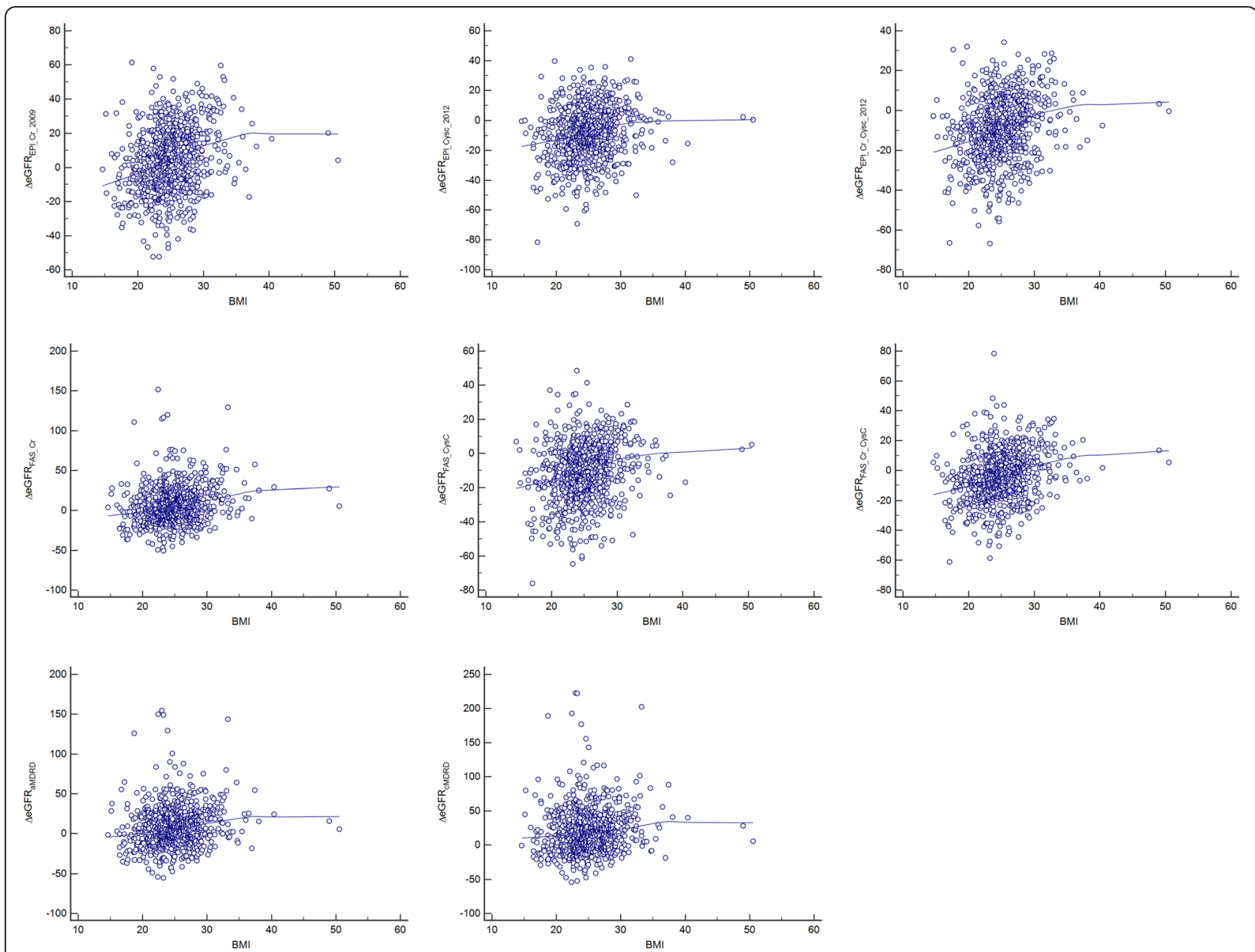

Fig. 1 Plot scatter diagrams of $\triangle \mathrm{eGFR}$ based on different formulas with the increase of $\mathrm{BMI}$

CKD stage of FAS_Cr_CysC eq. (71.1, 61.2, 70.0, 42.9 and $50.0 \%$ respectively) was not as good as EPI_Cr CysC_2012 equation.

\section{Diagnostic performance of each eGFR equation for predicting renal insufficiency in different BMI intervals}

The diagnostic performance for predicting renal insufficiency based on each eGFR equation in three BMI intervals was summarized and showed in Supplemental Table 4, 5 and 6 and Fig.3. In the $\mathrm{BMI}_{\mathrm{P} 25}$ interval, with a sensitivity of $89.7 \%$ and a specificity of $84.1 \%$, at a cutoff point of $67.1 \mathrm{~mL} / \mathrm{min} / 1.73 \mathrm{~m}^{2}$, eGFREPI_Cr_2009 got an $\mathrm{AUC}_{60}$ of 0.920 which had no significant difference compared with other equations $(p>0.05)$, suggesting appropriate diagnostic ability for predicting renal insufficiency. In $\mathrm{BMI}_{\mathrm{P} 25}$ interval, $\mathrm{eGFR}_{\mathrm{FAS} C \mathrm{Cr}}$ had similar performance with a sensitivity of $79.3 \%$, specificity of 88.1\%, and an $\mathrm{AUC}_{60}$ of 0.928 at a cut-off point of 56.6 $\mathrm{mL} / \mathrm{min} / 1.73 \mathrm{~m}^{2}$.

In BMI ${ }_{\mathrm{P} 25-75}$ interval, the cut-off point of eGFR $\mathrm{FAS}_{\mathrm{Cr}}$ CysC was $62.9 \mathrm{~mL} / \mathrm{min} / 1.73 \mathrm{~m}^{2}$, with an $\mathrm{AUC}_{60}$ of 0.941 which had no significant difference compared with other equations (except eGFR FAS_CysC $p=0.021$ ). When the cut-off values of eGFREPI_CysC_2012 and eGFREPI_ Cr_CysC_2012 were revised to 60.1 and $60.2 \mathrm{~mL} / \mathrm{min} /$ $1.73 \mathrm{~m}^{2}$ respectively, the sensitivity was increased to 90.3 and $91.8 \%$ respectively, but the specificity was decreased to 78.9 and $77.2 \%$ respectively. Looking back at eGFRFAS_Cr_CysC , when cut-off point of eGFR FAS_Cr_CysC $_{\text {was }}$ $62.9 \mathrm{~mL} / \mathrm{min} / 1.73 \mathrm{~m}^{2}$, the sensitivity was $92.5 \%$ and the specificity was $78.6 \%$, while after revising cut-off value to $60.0 \mathrm{~mL} / \mathrm{min} / 1.73 \mathrm{~m}^{2}$, the sensitivity was $87.3 \%$ and the specificity was $82.0 \%$, indicating that the diagnostic performance for predicting renal insufficiency was relatively stable. In $\mathrm{BMI}_{\mathrm{P} 75}$ interval, the optimal cut-off point of eGFR EPI_Cr_CySC_2012 $_{\text {for predicting renal insufficiency }}$ was $60.5 \mathrm{~mL} / \mathrm{min} / 1.73 \mathrm{~m}^{2}$, with an ideal sensitivity of $90.7 \%$, a specificity of $80.5 \%$, and an $\mathrm{AUC}_{60}$ of 0.919 $\left(P<0.05\right.$ vs. eGFR EPI_CysC_2012 $\left._{2}\right)$, highlighted itself. The optimal cut-off point of eGFR FAS_Cr_CysC $_{\text {for }}$ foredicting renal insufficiency was $61.5 \mathrm{~mL} / \mathrm{min} / 1.73 \mathrm{~m}^{2}$, with a sensitivity of $87.2 \%$, a specificity of $84.6 \%$, and an $\mathrm{AUC}_{60}$ of 


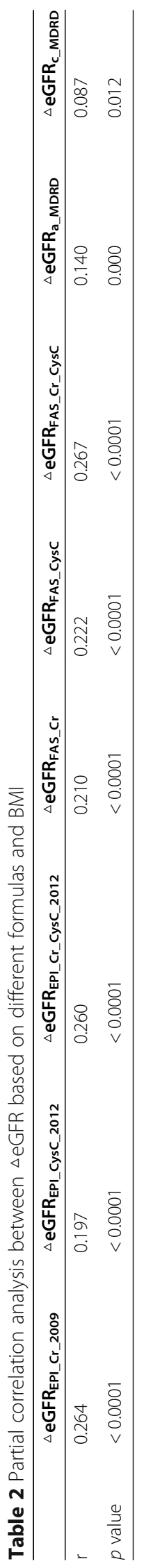




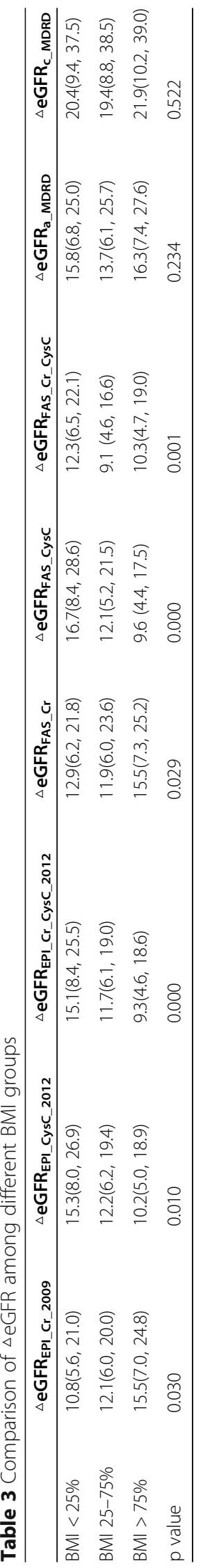



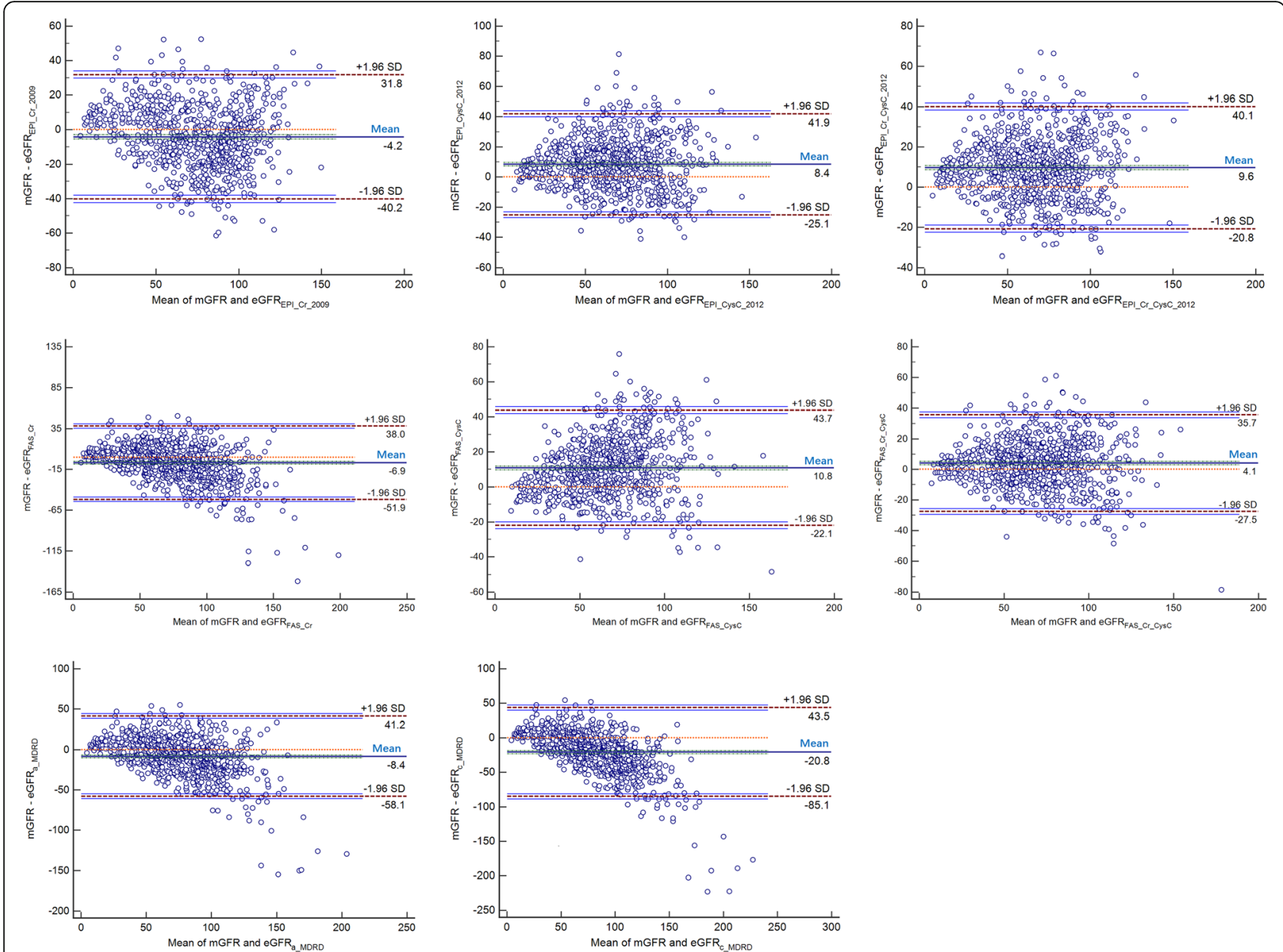

Fig. 2 Bland-Altman plots of the $\mathrm{mGFR}$ and eGFR $\left(\mathrm{mL} / \mathrm{min} / 1.73 \mathrm{~m}^{2}\right)$

Table 4 Comparison of bias and accuracy between eGFRs and mGFR in different BMI groups

\begin{tabular}{|c|c|c|c|c|c|c|c|c|}
\hline \multirow{2}{*}{$\begin{array}{l}\text { BMI } \\
\text { Equation }\end{array}$} & \multicolumn{2}{|l|}{ Total } & \multicolumn{2}{|l|}{$<25 \%$} & \multicolumn{2}{|l|}{$25-75 \%$} & \multicolumn{2}{|l|}{$>75 \%$} \\
\hline & $\begin{array}{l}\text { Bias } \\
\left(\mathrm{mL} / \mathrm{min} / 1.73 \mathrm{~m}^{2}\right) \\
\left({ }^{\circ} \mathrm{eGFR}, 95 \% \mathrm{Cl}\right)\end{array}$ & $\begin{array}{l}30 \% \\
\text { accuracy }\end{array}$ & $\begin{array}{l}\text { Bias } \\
\left(\mathrm{mL} / \mathrm{min} / 1.73 \mathrm{~m}^{2}\right) \\
(\triangle \mathrm{eGFR}, 95 \% \mathrm{Cl})\end{array}$ & $\begin{array}{l}30 \% \\
\text { accuracy }\end{array}$ & $\begin{array}{l}\text { Bias } \\
\left(\mathrm{mL} / \mathrm{min} / 1.73 \mathrm{~m}^{2}\right) \\
(\triangle \mathrm{eGFR}, 95 \% \mathrm{Cl})\end{array}$ & $\begin{array}{l}30 \% \\
\text { accuracy }\end{array}$ & $\begin{array}{l}\text { Bias } \\
\left(\mathrm{mL} / \mathrm{min} / 1.73 \mathrm{~m}^{2}\right) \\
(\triangle \mathrm{eGFR}, 95 \% \mathrm{Cl})\end{array}$ & $\begin{array}{l}30 \% \\
\text { accuracy }\end{array}$ \\
\hline eGFREPI_Cr_2009 & $-4.2(-5.5--3.0)^{\triangle}$ & $70.1 \%$ & $2.3(-0.1-4.8)^{\square}$ & $71.8 \%$ & $-4.0(-5.8--2.5)^{\Delta}$ & $74.7 \%$ & $-11.1(-13.5--8.4)^{\Delta}$ & $59.3 \%$ \\
\hline eGFR & $8.4(7.3-9.6)^{\Delta}$ & $74.0 \%$ & $13.1(10.7-15.7)^{\triangle}$ & $67.5 \%$ & $8.6(7.0-10.1)^{\Delta}$ & $75.9 \%$ & $3.3(1.2-5.5)^{\boldsymbol{\Lambda}}$ & $76.6 \%$ \\
\hline eGFREPI_Cr_CysC_2012 & $9.6(8.6-10.7)^{\Delta}$ & $74.1 \%$ & $15.2(13.1-17.3)^{\Delta}$ & $64.1 \%$ & $9.8(8.4-11.2)^{\Delta}$ & $75.4 \%$ & $3.8(1.7-5.8)^{\triangle}$ & $78.9 \%$ \\
\hline eGFR $R_{F A S}$ Cr & $-6.9(-8.5--5.4)^{\Delta}$ & $69.3 \%$ & $-0.7(-3.8-2.5)^{\circ}$ & $74.2 \%$ & $-7.1(-9.2--4.9)^{\Delta}$ & $70.6 \%$ & $\begin{array}{l}-12.9(-16.0-- \\
9.9)^{\Delta}\end{array}$ & $61.7 \%$ \\
\hline eGFRFAS_CysC & $10.8(9.7-11.9)^{\Delta}$ & $73.4 \%$ & $15.9(13.5-18.3)^{\Delta}$ & $64.1 \%$ & $11.0(9.5-12.6)^{\Delta}$ & $76.1 \%$ & $5.3(3.2-7.4)^{\Delta}$ & $77.0 \%$ \\
\hline eGFR FAS_Cr_CysC $_{\text {f }}$ & $4.1(3.0-5.1)^{\Delta}$ & $81.5 \%$ & $9.9(7.8-12.1)^{\Delta}$ & $77.5 \%$ & $4.0(2.5-5.5)^{\Delta}$ & $85.0 \%$ & $-1.8(-3.9-0.3)^{\bullet}$ & $78.5 \%$ \\
\hline eGFR $R_{a \_M D R D}$ & $-8.4(-10.2--6.7)^{\Delta}$ & $63.0 \%$ & $-3.7(-7.3--0.1) \boldsymbol{\Lambda}$ & $64.6 \%$ & $-8.5(-10.9--6.0)^{\Delta}$ & $65.0 \%$ & $-13.1(-16.3--9.9)^{\Delta}$ & $59.8 \%$ \\
\hline$e G F R_{C_{-} M D R D}$ & $\begin{array}{l}-20.8(-23.0- \\
-18.6)^{\Delta}\end{array}$ & $47.0 \%$ & $-8.8(-12.6--4.9)^{\Delta}$ & $45.5 \%$ & $\begin{array}{l}-20.5(-23.9- \\
-17.5)^{\Delta}\end{array}$ & $51.1 \%$ & $\begin{array}{l}-24.8(-28.6- \\
-20.5)^{\Delta}\end{array}$ & $40.2 \%$ \\
\hline
\end{tabular}

$\triangle$ Compared with mGFR, $P<0.01$;

$\triangle$ Compared with mGFR, $P<0.05$;

$\square$ Compared with mGFR, $\mathrm{P}=0.061$;

-Compared with mGFR, $P=0.401$

-Compared with mGFR, $\mathrm{P}=0.679$;

-Compared with mGFR, $\mathrm{P}=0.095$; 


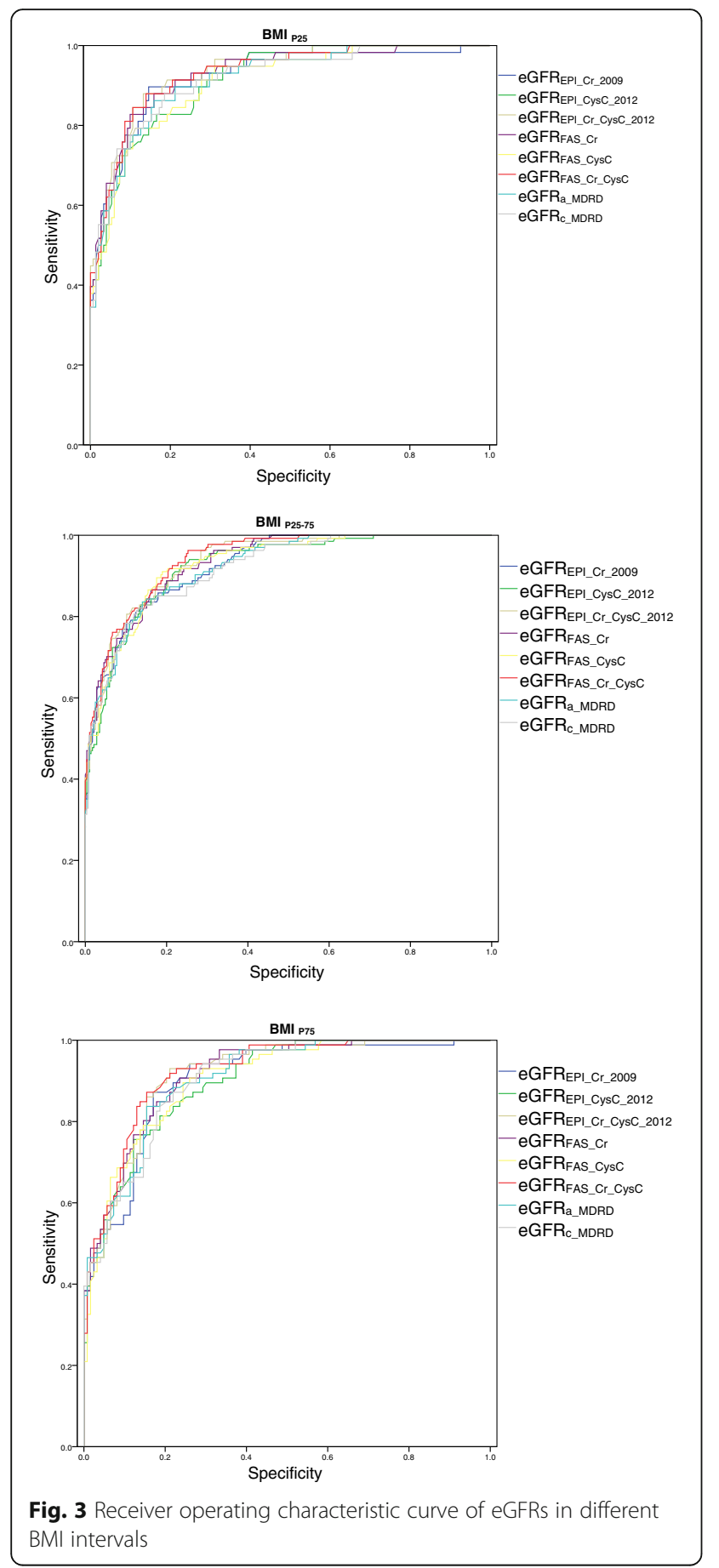

$0.922\left(P<0.05\right.$ vs. eGFR FAs_CysC $\left._{2}\right)$. It suggested that eGFR $\mathrm{E}_{-}$ PI_Cr_CysC_2012 and eGFR FAS_Cr_CysC $_{\text {Cad }}$ he strongest ability to predict renal insufficiency in $\mathrm{BMI}_{\mathrm{P} 75}$ interval.

\section{Discussion}

There is high disease burden of CKD in China [2]. The global increase in this disease is mainly driven by the increase in the prevalence of diabetes mellitus, hypertension, obesity, and aging. To make matters worse, the risk of death gradually increases with the deterioration of CKD [20]. Therefore, screening, diagnosis, and staging CKD early as well as accurately are more and more important. Estimating GFR accurately is crucial for clinical practice, research, and public health. Although Tc-99 m DTPA renal dynamic scintigraphy is a useful tool for clinicians in assessing renal function, this method cannot be regularly used in clinical practice. On the contrary, GFR estimated from equations is a convenient approach to assess patients' renal function. Due to the convenience of testing, it can be used as a method for largescale cases screening.

Each eGFR equation is established by statistically processing of certain population data, so it always performs less well outside the cohort in which they were developed [21]. All methods for the estimation of GFR have limitations, so no equation can perform best in all populations. Obesity is associated with a risk of CKD and is highly prevalent among patients with CKD $[22,23]$. In our study, the average BMI of the cases was 24.8, of which 25.1 for males and 24.2 for females. A large number of patients were overweight or obese. Therefore, it inspired us to consider the influence of BMI, which can partly reflect the difference of body. If we properly handled this influence, can we make the best use of each eGFR equation? There are few studies on the applicability of different eGFR equations in different BMI intervals. In this study, we evaluated the value of different eGFR formulas in different BMI intervals.

After being analyzed by Bland-Altman plots, biases of eGFR $_{\text {FAS_Cr_CysC }}$ and eGFR EPI_Cr_2009 $_{\text {_ere }}$ wuch less than that of others on the whole, showing the best agreement with mGFR. In $\mathrm{BMI}_{\mathrm{P} 25}$ interval, eGFR $\mathrm{FAS}_{\mathrm{F}} \mathrm{Cr}$ and eGFR EPI_Cr_2009 formulas had optimal accuracy, excellent ability to classify CKD stages, and best diagnostic performance for predicting renal insufficiency. In $\mathrm{BMI}_{\mathrm{P} 25-75}$ interval, eGFR $\mathrm{FAS}_{\text {_Cr_CysC }}$ was the best one, with optimal accuracy and excellent ability in staging CKD2 and CKD3. In $\mathrm{BMI}_{75}$ interval, eGFR EPI_Cr_- $_{-}$ CysC_2012 equation showed excellent accuracy, stable identification power for CKD stages and the strongest ability to predict renal insufficiency. In $\mathrm{BMI}_{75}$ interval, the accuracy and ability to predict renal insufficiency of eGFR $\mathrm{FAS}_{\text {_CC_CYsC }}$ was similar to that of eGFR $\mathrm{EPI}_{-} \mathrm{Cr}_{-}-$ CysC_2012. However, eGFR FAS_Cr_CysC $_{\text {was }}$ not as good as eGFRE PI_Cr_Cys__2012 $_{2}$ equation in identifying CKD stages. We found Scr-cysC-based eGFR equations had superiority in evaluating eGFR compared to the Scr-based formulas in overweight or obese people.

It's well known that $\mathrm{SCr}$ has limitations including its insensitivity to underlying changes in kidney function and the numerous non-kidney factors that are 
incompletely accounted for in equations to eGFR [24]. Although as an endogenous biomarker, concentration of cysC also can be affected by other non-renal determinants, such as obesity, thyroid disorders, diabetes, and inflammation, however, compared to $\mathrm{SCr}$, cysC appears to be less affected by age, race, sex, muscle mass, or dietary intake $[25,26]$. It is increasingly accepted to use the use equations based on cystatin $C$ or combined creatinine and cystatin $C$ [27]. In fact, kidney function assessment in obese patients is challenging. Nephron number does not change with weight gain, and the increase of GFR observed in obese patients reflects compensatory hyperfiltration of nephrons. This hyperfiltration in obese patients can become maladaptive and is largely unaccounted for in existing eGFR equations [28]. According to our research, it may be acceptable to choose an eGFR formula based on combined creatinine and cystatin $C$ before a better formula appears. It is worth mentioning that, our reseach proves that, the novel FAS equations [11] are suitable for Chinese population, and even have superiority compared to other formulas in many cases, especially the eGFR $\mathrm{FAS}_{\text {_Cr_CysC }}$ equation. In a multicenter study of 1184 patients in China, the performance of the eGFR FAS_Cr_CysC $_{\text {Cquation was better }}$

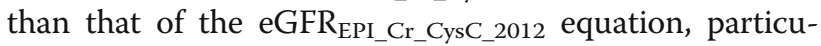
larly in the elderly [29]. It may be necessary to further modify the FAS equation from a larger-scale study to make it more suitable for the Chinese population.

Exactly, each eGFR formula shows different clinical value in different BMI intervals. Therefore, the BMI of patients with CKD is an aspect worthy considering when choosing the appropriate eGFR equation. Which is the best choice? In our study, in normal or low-weight population, the formula based on serum creatinine is preferred, and in overweight or obese population, the formula based on serum creatinine and cystatin $C$ may be more suitable. The reason may be that the combination of both biomarkers can cancel out the non-GFRrelated factors influencing creatinine and cystatin $\mathrm{C}$ in different directions compared with mGFR. Steubl et al. suggest that combining metabolites or proteins in equations to minimize the influence of nonkidney-related parameters appears to be a promising approach which is consistent with our view [30].

Our research had some strengths such as on ethnic factors that all were from Chinese population, concentrative age range, common high-risk diseases for CKD. These favoured us to identify the appropriate eGFR equation for Chinese population while considering the impact of BMI. However, it needs to be verified and confirmed by different types of studies based on a larger population. More comparative studies on different types of samples are needed to further illuminate which biomarkers are better tools for diagnosis and prognosis of CKD.
Nevertheless, our study has some limitations. Firstly, we did not obtain specific data such as appendicular lean mass index (ALMI) and total body fat percentage (TBF\%) measured by dual-energy x-ray absorptiometry (DXA) of body composition [31,32], so we cannot refine the population in the BMI intervals. Secondly, we didn't have enough data of proteinuria to define renal dysfunction because we only got one urine protein test result for each patient's first morning urine. Thirdly, as it was a cross-sectional analysis, and a retrospective, singlecenter study, the results of this study should be carefully applied in practical clinical practice. Finally, although we assessed eight eGFR equations that were commonly used, there are also some other equations which were well praised were not included in our study.

In conclusion, after comprehensive analysis of factors that included consistency, accuracy, classification ability and diagnostic performance, we tend to suggest that choosing eGFR mate GFR of patients when BMI is around $20.9 \mathrm{~kg} / \mathrm{m}^{2}$, eGFR $_{\text {FAS_Cr_CysC }}$ for overweight patients (BMI around $24.8 \mathrm{~kg} / \mathrm{m}^{2}$ ), and eGFR EPI_Cr_CysC_2012 $_{2}$ for obese patients (BMI is about $28.9 \mathrm{~kg} / \mathrm{m}^{2}$ ).

\section{Supplementary Information}

The online version contains supplementary material available at https://doi. org/10.1186/s12882-021-02395-x.

Additional file 1: Supplemental Table 1. CKD stage classification based on eGFRs in BMlp25 interval. Supplemental Table 2. CKD stage classification based on eGFRs in BMIP25-75 interval. Supplemental

Table 3. CKD stage classification based on eGFRs in BMlp75 interval. Supplemental Table 4. Diagnostic performance in $\mathrm{BMI}_{\mathrm{P} 25}$ interval of eGFRs for predicting renal insufficiency $(\mathrm{mL} / \mathrm{min} / 1.73 \mathrm{~m} 2)$. Supplemental Table 5. Diagnostic performance in $\mathrm{BMI}_{\mathrm{P} 25-75}$ interval of eGFRs for predicting renal insufficiency $(\mathrm{mL} / \mathrm{min} / 1.73 \mathrm{~m} 2)$. Supplemental Table 6 . Diagnostic performance in $\mathrm{BMI}_{\mathrm{P} 75}$ interval of eGFRs for predicting renal insufficiency $(\mathrm{mL} / \mathrm{min} / 1.73 \mathrm{~m} 2)$.

Additional file 2.

\section{Acknowledgments}

The research team acknowledge the support of the National Natural Science Foundation of China.

\section{Authors' contributions}

Jiayong Li and Xiang Xu designed the study. Jialing Luo, Wenjing Chen and Man Yang collected data. Ling Wang and Nan Zhu analyzed and explained the data. Weijie Yuan critically reviewed the content of the article. Lijie Gu statistically analyzed and wrote the article. All authors reviewed and approved the manuscript.

\section{Funding}

This study was supported in part by grants from Young Scientists Fund of the National Natural Science Foundation of China (No. 81900671).

Availability of data and materials

All data analysed during this study are included in Supplementary Information Files and also available from the corresponding author on reasonable request. 


\section{Declarations}

\section{Ethics approval and consent to participate}

Research has been conducted in accordance with the Declaration of Helsinki and was approved by the Ethics Committee of Shanghai General Hospital. Written informed consent was obtained from all participants. All methods were carried out in accordance with the relevant guidelines and regulations.

\section{Consent for publication}

Written informed consent for publication was obtained from all participants.

\section{Competing interests}

The authors declare that they have no competing interests.

\section{Author details}

${ }^{1}$ Clinical Laboratory Medicine Center, Shanghai General Hospital, Shanghai Jiao Tong University School of Medicine, Shanghai 200080, China. 2Department of Nephrology, Shanghai General Hospital, Shanghai Jiao Tong University School of Medicine, Shanghai 200080, China.

Received: 28 October 2020 Accepted: 4 May 2021

Published online: 25 May 2021

\section{References}

1. Kidney Disease: Improving Global Outcomes (KDIGO) CKD Work Group. KDIGO 2012 Clinical Practice Guideline for the Evaluation and Management of Chronic Kidney Disease. Kidney Int. 2013;Suppl. 3(5):1-150. https://doi. org/10.1053/j.ajkd.2014.01.416.

2. Jha V, Garcia-Garcia G, Iseki K, Li Z, Naicker S, Plattner B, et al. Chronic kidney disease: global dimension and perspectives. Lancet. 2013;382:260-72. https://doi.org/10.1016/S0140-6736(13)60687-X.

3. GBD Chronic Kidney Disease Collaboration. Global, regional, and national burden of chronic kidney disease, 1990-2017: a systematic analysis for the global burden of disease study 2017. Lancet. 2020;395(10225):709-33. https://doi.org/10.1016/50140-6736(20)30045-3.

4. Trimarchi H, Muryan A, Martino D, Toscano A, Iriarte R, Campolo-Girard V, et al. Creatinine- vs. cystatin C-based equations compared with 99mTcDTPA scintigraphy to assess glomerular filtration rate in chronic kidney disease. J Nephrol. 2012;25(6):1003-15. https://doi.org/10.5301/jn.5000083.

5. Vinge $E$, Lindergard B, Nilsson-Ehle $P$, Grubb A. Relationships among serum cystatin C, serum creatinine, lean tissue mass and glomerular filtration rate in healthy adults. Scand J Clin Lab Invest. 1999;59(8):587-92. https://doi. org/10.1080/00365519950185076.

6. Bouquegneau A, et al. Modification of Diet in Renal Disease versus Chronic Kidney Disease Epidemiology Collaboration equation to estimate glomerular filtration rate in obese patients. Nephrol Dial Transplant. 2013:28, iv122-iv130. https://doi.org/10.1093/ndt/gft329.

7. Lemoine S, Guebre-Egziabher F, Sens F, Nguyen-Tu MS, Juillard L, Dubourg $L$, et al. Accuracy of GFR estimation in obese patients. Clin J Am Soc Nephrol. 2014;9(4):720-7. https://doi.org/10.2215/CJN.03610413.

8. Wasén E, Isoaho R, Mattila K, Vahlberg T, Kivelä SL, Irjala K. Serum cystatin C in the aged: relationships with health status. Am J Kidney Dis. 2003;42(1): 36-43. https://doi.org/10.1016/s0272-6386(03)00406-2.

9. Levey AS, Stevens LA, Schmid CH, Zhang $Y(L)$, Castro AF III, Feldman HI, et al. A new equation to estimate glomerular filtration rate. Ann Intern Med. 2009;150(9):604-12. https://doi.org/10.7326/0003-4819-150-9-2 00905050-00006.

10. Inker LA, Schmid $\mathrm{CH}$, Tighiouart $\mathrm{H}$, Eckfeldt JH, Feldman $\mathrm{HI}$, Greene $\mathrm{T}$, et al. Estimating glomerular filtration rate from serum creatinine and cystatin C. N Engl J Med. 2012;367(1):20-9. https://doi.org/10.1056/NEJMoa1114248.

11. Pottel H, Delanaye P, Schaeffner E, Dubourg L, Eriksen BO, Melsom T, et al. Estimating glomerular filtration rate for the full age spectrum from serum creatinine and cystatin C. Nephrol Dial Transplant. 2017;32(3):497-507. https://doi.org/10.1093/ndt/gfw425.

12. McKillop DJ, Cairns B, Duly E, Van Drimmelen M, Ryan M. The effect of serum creatinine method choice on estimated glomerular filtration rate determined by the abbreviated MDRD formula. Ann Clin Biochem. 2006; 43(Pt 3):220-2. https://doi.org/10.1258/000456306776865098.

13. Ma YC, Zuo L, Chen JH, Luo Q, Yu XQ, Li Y, et al. Modified glomerular filtration rate estimating equation for Chinese patients with chronic kidney disease. J Am Soc Nephrol. 2006;17(10):2937-44. https://doi.org/10.1681/A SN.2006040368.

14. Smirnov N. Table for estimating the goodness of fit of empirical distributions. Ann Math Stat. 1948;19(2):279-81. https://doi.org/10.1214/a oms/1177730256.

15. Hart A. Mann-Whitney test is not just a test of medians: differences in spread can be important. BMJ. 2001;323(7309):391-3. https://doi.org/10.113 6/bmj.323.7309.391.

16. Bland JM, Altman DG. Statistical methods for assessing agreement between two methods of clinical measurement. Lancet. 1986;1:307-10.

17. Chi XH, Li GP, Wang QS, Qi YS, Huang K, Zhang Q, et al. CKD-EPI creatininecystatin $\mathrm{C}$ glomerular filtration rate estimation equation seems more suitable for Chinese patients with chronic kidney disease than other equations. BMC Nephrol. 2017;18(1):226. https://doi.org/10.1186/s12882-017-0637-z.

18. Landis JR, Koch GG. The measurement of observer agreement for categorical data. Biometrics. 1977;33(1):159-74. https://doi.org/10.2307/2529310.

19. DeLong ER, DeLong DM, Clarke-Pearson DL. Comparing the areas under two or more correlated receiver operating characteristic curves: a nonparametric approach. Biometrics. 1988;44(3):837-45. https://doi.org/10.2307/2531595.

20. Sarnak MJ, Amann K, et al. Chronic Kidney Disease and Coronary Artery Disease: JACC State-of-the-Art Review. J Am Coll Cardiol. 2019;74(14):182338. https://doi.org/10.1016/j.jacc.2019.08.1017.

21. Lamb EJ, Tomson CR, Roderick PJ, clinical sciences reviews Committee of the Association for clinical biochemistry. Estimating kidney function in adults using formulae. Ann Clin Biochem. 2005;42(Pt 5):321-45. https://doi. org/10.1258/0004563054889936 PMID: 16168188.

22. Stenvinkel P, Zoccali C, Ikizler TA. Obesity in CKD--what should nephrologists know? J Am Soc Nephrol. 2013;24(11):1727-36. https://doi. org/10.1681/ASN.2013040330.

23. Wang Y, Chen X, Song Y, Caballero B, Cheskin LJ. Association between obesity and kidney disease: a systematic review and meta-analysis. Kidney Int. 2008;73(1):19-33. https://doi.org/10.1038/sj.ki.5002586.

24. Levey AS, Inker LA. Assessment of glomerular filtration rate in health and disease: a state of the art review. Clin Pharmacol Ther. 2017;102(3):405-19. https://doi.org/10.1002/cpt.729 Epub 2017 Jun 5. PMID: 28474735.

25. Stevens LA, Schmid CH, Greene T, Li L, Beck GJ, Joffe MM, et al. Factors other than glomerular filtration rate affect serum cystatin C levels. Kidney Int. 2009;75(6):652-60. https://doi.org/10.1038/ki.2008.638 Epub 2008 Dec 31 PMID: 19119287; PMCID: PMC4557800.

26. Teaford HR, Barreto JN, Vollmer KJ, Rule AD, Barreto EF, Cystatin C. A Primer for Pharmacists. Pharmacy (Basel). 2020;8(1):35. https://doi.org/10.3390/pha rmacy8010035 PMID: 32182861; PMCID: PMC7151673.

27. Yang $M, X u$ G, Ling L, Niu J, Lu T, Du X, et al. Performance of the creatinine and cystatin C-based equations for estimation of GFR in Chinese patients with chronic kidney disease. Clin Exp Nephrol. 2017;21(2):236-46. https:// doi.org/10.1007/s10157-016-1273-9 Epub 2016 Apr 28. PMID: 27125433.

28. Chang AR, Zafar W, Grams ME. Kidney Function in Obesity-Challenges in Indexing and Estimation. Adv Chronic Kidney Dis. 2018;25(1):31-40. https:// doi.org/10.1053/j.ackd.2017.10.007 PMID: 29499884; PMCID: PMC5836495.

29. Yong Z, Li F, Pei X, Liu X, Song D, Zhang X, et al. A comparison between 2017 FAS and 2012 CKD-EPI equations: a multi-center validation study in Chinese adult population. Int Urol Nephrol. 2019;51(1):139-46. https://doi. org/10.1007/s11255-018-1997-4 Epub 2018 Oct 24. PMID: 30357600.

30. Steubl $D$, Inker LA. How best to estimate glomerular filtration rate? Novel filtration markers and their application. Curr Opin Nephrol Hypertens. 2018; 27(6):398-405. https://doi.org/10.1097/MNH.0000000000000444 PMID: 30063487.

31. Thibault R, Pichard C. The evaluation of body composition: a useful tool for clinical practice. Ann Nutr Metab. 2012;60(1):6-16. https://doi.org/10.1159/ 000334879.

32. Marinangeli CP, Kassis AN. Use of dual X-ray absorptiometry to measure body mass during short- to medium-term trials of nutrition and exercise interventions. Nutr Rev. 2013;71(6):332-42. https:/doi.org/10.1111/nure.12025.

\section{Publisher's Note}

Springer Nature remains neutral with regard to jurisdictional claims in published maps and institutional affiliations. 